\title{
Removal of Toxic Metals from Sewage Sludge Through Chemical, Physical, and Biological Treatments-a Review
}

\author{
Franciele Pereira Camargo • Paulo Sérgio Tonello • \\ André Cordeiro Alves dos Santos • \\ Iolanda Cristina Silveira Duarte
}

Received: 19 August 2016/Accepted: 26 October 2016/Published online: 7 November 2016

(C) Springer International Publishing Switzerland 2016

\begin{abstract}
The implantation of wastewater treatment systems aims to minimize environmental impacts, but ultimately generates waste materials, such as sewage sludge, which must be properly discarded. Final disposal in landfills, and incineration are the most commonly used disposal methods, but both constitute a threat to the soil, water, air, and food chain. The most suitable alternative for the disposal of sewage sludge is its use as fertilizer, due to the nutrients in its composition, such as nitrogen, phosphorus, and organic carbon. However, the presence of potentially toxic metals is the main factor that limits such use. Many techniques have been employed in attempt to remove these toxic metals, including physical, chemical, and biological treatments, but the high cost of the physical and chemical treatments, as well as the risk of causing secondary pollution, makes this type of sewage sludge treatment an unsatisfactory option. Therefore, removing toxic metals through biological treatments has become an increasingly popular choice, as such treatments have been shown to be the most economically and environmentally beneficial methods. The aim of the present study was to
\end{abstract}

F. P. Camargo $(\bowtie) \cdot$ A. C. A. dos Santos - I. C. S. Duarte Laboratório de Microbiologia Ambiental, Universidade Federal de São Carlos-UFSCar, Rodovia João Leme dos Santos Km 101, CEP 18052-780 Sorocaba, SP, Brazil

e-mail: francielep.camargo@hotmail.com

P. Sérgio Tonello

Laboratório de Física Ambiental, Universidade Estadual Paulista

"Júlio de Mesquita Filho"-UNESP, Avenida Três de Março, 511,

Alto da Boa Vista, CEP 18087-180 Sorocaba, SP, Brazil provide a review of some of the most common alternative treatments for the incineration and disposal of sludge in landfills, emphasizing the physical, chemical, and biological processes that enable the removal of potentially toxic metals, for the purpose of obtaining a final product which can be used as fertilizers in farm soils.

Keywords Heavy metals · Metal solubilization · Wastewater treatment $\cdot$ Bioleaching

\section{Introduction}

One of the consequences of population growth and economic activity is an exponential increase in waste generation of anthropogenic origin, such as sewage (Azizi et al. 2013). Sewage treatment systems are aimed at minimizing the environmental impacts caused by the release of this substance into the environment, but such processes can also generate secondary waste that must be disposed of properly (Wei et al. 2014), as it can contaminate soil and water bodies and interfere with the food chain, threatening the ecosystem balance (Chen et al. 2012).

Secondary wastes formed during the wastewater treatment process are usually solid, such as meshed material, sand, scum, and sludge. The latter is a byproduct of wastewater treatment (Chen et al. 2012) and may take the form of primary sludge (sedimented solids), biological or secondary sludge (microbial biomass), and tertiary sludge, which originates from 
physical-chemical treatments such as precipitation with metals, salts, or calcium oxide (CaO) (Andreoli 2001).

The cost of managing sludge treatment can reach up to $60 \%$ of the total operational expenditure of a Wastewater Treatment Plant (WWTP) (Chen et al. 2012), and it is estimated that approximately 200 thousand tons of dry sludge mass are generated each year in Brazil only (Andreoli 2001; Villar and Garcia 2003). However, in 2012 in the European Union, these residues still did not have a standardized final destination (Kelessidis and Stasinakis 2012). Thus, emergency solutions are often used, which may compromise the benefits of the entire sewage treatment process.

Sewage sludges have desirable characteristics for use as agricultural fertilizer, such as a high concentration of organic matter and nutrients, as well as undesirable characteristics, such as considerable quantities of potentially toxic pathogens and metals (Li et al. 2012; Wei et al. 2014; Wong 2005). Moreover, even the desirable characteristics can be harmful to the environment when in high concentrations, if the waste is improperly disposed of, or in other words, disposed in soil without previous evaluation of its composition.

Nitrogen and phosphorus - which are abundant in sewage sludges, reaching concentrations ranging from 1.5 to $6.0 \%$ and from 0.8 to $11.0 \%$ of total solids, respectively (Pathak et al. 2009) - are considered limiting elements for the growth of various organisms (Ebbers et al. 2015), such as algae. The improper disposal of sewage sludge can therefore lead to eutrophication of water systems (Cieslik et al. 2015).

The final characteristics of sludges depend on the treatment system and where the wastewater originates from. For example, sewage sludges arising exclusively from residential wastewater treatments systems usually contain smaller amounts of certain pollutants, such as toxic metals, than sludges from treatment systems of industrial wastewater or mixed use systems. However, the sludges from wastewater are more likely to have high amounts of pathogens and can vary according to the health conditions of the population (Andreoli 2001).

Sewage sludges can also contain organisms that are harmful to the health of animals and plants, such as pathogens and parasites, including helminths, protozoa, fungi, bacteria, and even viruses (Wei et al. 2014). The improper disposal of sludge can be an aggravating factor in the incidence of diseases caused by these organisms, and even non-pathogenic microorganisms can cause damage to the environment, as they can interfere with the natural microbiota of the soil (Wong 2005).

Metals can be considered the major inorganic contaminants in sewage sludge (Wong 2005) and can vary from 0.5 to $4 \%$ of the dry weight of the sewage (Pathak et al. 2009). They can occur in different concentrations, depending on the type and origin of the effluent, and may be present in several forms, dependent upon the $\mathrm{pH}$ of the substrate or other factors, such as humidity, the amount of organic matter, and the type of metal and its interaction with other elements (Jjemba 2005). The presence of toxic metals is one of the main factors limiting the application of sewage sludge as a fertilizer (Ebbers et al. 2015).

Metals commonly found in sewage sludge are lead $(\mathrm{Pb})$, cadmium $(\mathrm{Cd})$, nickel $(\mathrm{Ni})$, chromium $(\mathrm{Cr})$, copper $(\mathrm{Cu})$, and zinc $(\mathrm{Zn})$. Some of these, in appropriate concentrations, are considered micronutrients, while others have no known function on plants and animals (Pathak et al. 2009). One of the problems with these metals is that, unlike most pollutants, they cannot be degraded. As a result, when present in food sources containing industrial waste, they can eventually be swallowed and metabolized by plants and animals, and bioaccumulate (Elicker et al. 2014).

According to NBR 10004 (ABNT 2004), solid wastes contaminated with heavy metals are considered as class 1 (level of dangerousness), since they represent risks to the environment, and therefore must be treated and disposed of properly. In Brazil, the National Solid Waste Policy, Law 12.305/2010 is the most recent law regulating the disposal of solid waste (Brasil 2010). It does not, however, address waste contaminated by heavy metals. However, resolution n ${ }^{\circ} 375 / 2006$ of the National Environmental Council (CONAMA) regulates the agricultural use of sewage sludge treatment in relation to the maximum contaminant concentrations (toxic metals and pathogens) permitted for this purpose (CONAMA 2006).

In São Paulo, Brazil, the Society of Environmental Sanitation Technology (CETESB) (current Technical Standard P4.230) regulates the application of sludge from biological treatment systems in agricultural areas. The organic and inorganic pollutant limits of this standard were based on criteria recommended by the US Environmental Protection Agency (USEPA), USA (CETESB 1999).

Although sludge disposal in landfills and by incineration are considered the most frequently used disposal 
methods, the latter should not be considered as a final disposal method, as the ashes it generates require proper disposal and can also cause damage to the environment (Deng et al. 2009). It is also a highly expensive process (Wei et al. 2014).

Organic matter is considered one of the most important sources of nutrients in soil (Domínguez-Crespo et al. 2012; Wong 2005), so the addition of sewage sludge, which is rich in such matter, can improve both the chemical and physical conditions of soils (both by improving its nutritional status and stabilizing its $\mathrm{pH}$ due to the buffering power of the sludge) (Deng et al. 2009). Clayey soils, for example, become more porous through the addition of sewage sludge, providing better conditions for root development and aeration, while in sandy soils, this process causes aggregation of the particles, increasing the water retention power of the soil, thus avoiding, for example, erosion (Wei et al. 2014; Wong 2005).

Many techniques have been employed in an attempt to improve the physical and chemical characteristics of sewage sludge and remove the toxic metals it contains. Among the most common physical treatments are heat treatment (Shi et al. 2013) and electroremediation (Elicker et al. 2014), while the addition of organic acidifying and inorganic products (Deng et al. 2009) or ionic reagents (Fuerhacker et al. 2012) or chelating (Wu et al. 2015) are considered the most common forms of chemical treatment.

The high cost of physical and chemical treatments, as well as the risk of secondary pollution, can discourage the use of these processes for the treatment of sewage sludge (Pathak et al. 2009). Thus, the removal of toxic metals through biological treatments, such as the application of biosurfactants (Maier et al. 2001; Yang et al. 2016), bioleaching (Cheng et al. 2005; Fang and Zhou 2007; Wen et al. 2013; Wong et al. 2004; Zhou et al. 2013), and vermicomposting (Azizi et al. 2013), has been attracting increasing attention as they have been shown to be economically and environmentally advantageous.

The objective of the present study was to provide an overview of alternative treatments for incineration and the disposal of biological sewage sludge in landfills, with the emphasis on processes that enable the removal of toxic metals, indicating their advantages and limitations, and where possible, propose amendments and suggestions for greater efficiency in the chosen process.

\section{Sewage Sludge Treatment-Most Common Techniques to Metal Removal}

Studies related to one of the three possible metal removal methods in sewage sludge treatment - chemical, biological, and physical - have increased in quantity over the years (Fig. 1). Chemical treatments have traditionally been the most studied form, although biological treatments have now gained equal prominence, while physical treatments remain comparatively less addressed, despite their remarkable efficiency in the removal of various metals in a short time (Table 1).

Concerns over the presence and the possibility of removal of potentially toxic metals in sewage began in the mid-1970s with studies such as that by Oliver and Cosgrove (1974), which monitored the presence of various metals in an activated sewage sludge treatment system, monitoring the levels of these elements in the influent and effluent and evaluating the potential of this treatment for their removal. These authors concluded that the treatment is valid for this purpose due to achieving an overall removal efficiency of chromium $(\mathrm{Cr})$, copper $(\mathrm{Cu})$, iron $(\mathrm{Fe})$, lead $(\mathrm{Pb})$, and zinc $(\mathrm{Zn})$ in the treated sewage of around $>50,59,47,50$, and $30 \%$, respectively. However, the metals removed during the sewage treatment are accumulated in the solid phase of the sewage, or in other words, in sewage sludge.

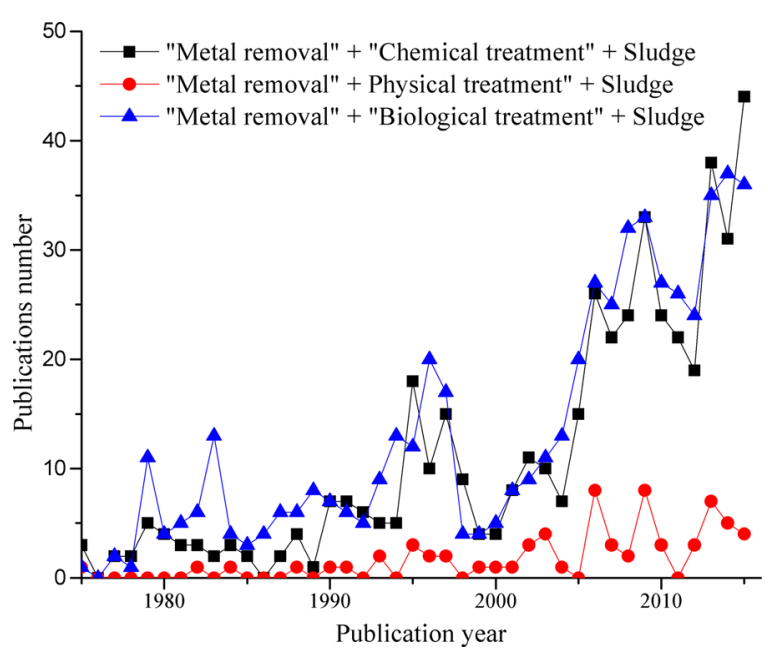

Fig. 1 Comparison between publications on the removal of metal from sewage sludge through different treatments. The search was made in the Science Direct database, comparing publications containing the words "metal removal", "chemical/physical/biological treatment" + "sludge" between the years 1975-2015 
Table 1 Summary of major chemical (1) physical (2) and biological (3) methods in the removal of toxic metals in sewage sludge

\begin{tabular}{|c|c|c|c|c|c|c|c|c|c|}
\hline \multicolumn{2}{|c|}{ Treatment } & \multirow{3}{*}{$\begin{array}{l}\text { Time } \\
72 \mathrm{~h}\end{array}$} & \multicolumn{6}{|c|}{ Metal solubilization (\%) } & \multirow{3}{*}{$\begin{array}{l}\text { Reference } \\
\text { Wu et al. (2015) }\end{array}$} \\
\hline & & & \multirow{2}{*}{$\frac{\mathrm{Zn}}{32}$} & \multirow{2}{*}{$\frac{\mathrm{Ni}}{82}$} & \multirow{2}{*}{$\frac{\mathrm{Cd}}{89}$} & \multirow{2}{*}{$\frac{\mathrm{Cu}}{84}$} & \multirow{2}{*}{$\begin{array}{c}\mathrm{Cr} \\
-\end{array}$} & \multirow{2}{*}{$\frac{\mathrm{Pb}}{-}$} & \\
\hline 1 & Chelating addition & & & & & & & & \\
\hline 1 & Acidification & $20 \mathrm{~min}$ & 82 & - & - & 09 & - & 87 & Deng et al. (2009) \\
\hline 1 & Ionic extraction & $24 \mathrm{~h}$ & $>90$ & $>90$ & $>85$ & 90 & $>90$ & $>85$ & Fuerhacker et al. (2012) \\
\hline 2 & Electroremediation & $40 \mathrm{~h}$ & 68 & - & - & 55 & 55 & 72 & Elicker et al. (2014) \\
\hline 2 & Electrodialysis & $24 \mathrm{~h}$ & 85 & 56 & 31 & 22 & 06 & 01 & Ebbers et al. (2015) \\
\hline 2 & Electrokinesis & $24 \mathrm{~h}$ & 95 & 90 & - & 96 & 68 & 19 & Wang et al. (2005) \\
\hline 2 & Heat treatment & $01 \mathrm{~h}$ & 86 & 72 & 94 & 97 & 74 & 11 & Shi et al. (2013) \\
\hline 3 & Bioleaching & 12 days & 88 & - & - & 79 & - & 50 & Wen et al. (2013) \\
\hline 3 & Bioleaching & 08 days & 99 & 84 & - & 74 & 65 & 58 & Wong et al. (2004) \\
\hline 3 & Vermicomposting & 105 days & - & - & 37 & 88 & 81 & 97 & Azizi et al. (2013) \\
\hline 3 & Biosurfactants & 05 days & 44 & - & 38 & 24 & - & 32 & Yang et al. (2016) \\
\hline 3 & Biosurfactants & $24 \mathrm{~h}$ & - & - & - & 59 & - & - & Maier et al. (2001) \\
\hline
\end{tabular}

All figures have been rounded to two digits for easy reading

\subsection{Chemical Treatments}

Chemical treatments have received much attention due to their efficiency and simplicity and also due to the short contact time required between the reagent and the sludge. This type of treatment is based on the principle that the balance between solubility and metal adsorption/complexation is directly related to the $\mathrm{pH}$ of the substrate, as metals can be found in sewage sludge in several forms, which are generally $\mathrm{pH}$ dependent (Jjemba 2005). Pb, for example, reacts to the $\mathrm{pH}$, becoming insoluble in alkaline conditions and remaining in higher concentrations in the solid phase. Other compounds react to the $\mathrm{pH}$ of the sludge in a similar way, alternating between the liquid phase and the solid phase (Andreoli 2001).

Various acids may be used in the sludge acidification process, both inorganic (nitric acid, sulfuric acid, and hydrochloric) and organic (oxalic acid and citric acid), and choosing the best reagent depends mainly on the type of metal to be extracted. Among these acids, hydrochloric acid has been shown to be the most effective in the solubilization of most metals (Qi-Tang et al. 1998), although Deng et al. (2009) reported that the use of nitric acid is advantageous because the nitrogen present in the acid may be used by plants if the sludge is applied to the soil after treatment.
An attempt to improve the acidification method using nitric acid and sound waves (ultrasound) for removal of the metals $\mathrm{Cu}, \mathrm{Zn}$, and $\mathrm{Pb}$ was described by Deng et al. (2009). The authors concluded that $0.325 \mathrm{M}$ would be the optimum concentration of nitric acid for solubilizing the metals analyzed, reaching a $\mathrm{pH}$ of 0.75 and solubilizing up to $9.5 \% \mathrm{Cu}, 82.2 \% \mathrm{Zn}$, and $87.3 \% \mathrm{~Pb}$. In this review, the technique is considered as chemical since the application of sound waves alone is not sufficient for the removal of metals, in other words, it is used only for speeding up the reactions.

Despite its advantages, the high cost of acidification is the major impediment to its application on a large scale (Deng et al. 2009), as well as the risk of secondary pollution that it brings (Pathak et al. 2009).

In addition to acidification, the stabilization of sewage sludge by alkalizing is also a widely used technique. However, it is more applicable for preventing the proliferation of pathogens than for the removal of metals, as the precipitates (insoluble metal hydroxides) formed in alkaline conditions are formed only in sludges with high concentrations of metals, and are difficult to remove from the raw sludge (Wong 2005).

Ion exchange treatment is a chemical method that consists of a process where undesirable ions such as metals are replaced by other ions, usually nonpollutants (Dabrowski et al. 2004). Although most of 
the research into the potential application of ionic reagents for the purpose of removing metal concentrates takes the form of the treatment of liquid substrates, Fuerhacker et al. (2012) studied the effects of the application of four different types of ionic reagents in sewage sludge, all with a base of quaternary ammonium and phosphonium. The results obtained for triexil (tetradecyl) phosphonium thiosalicylate $\left(1 \mathrm{~g} \mathrm{~L}^{-1}\right)$ showed that this method is also very effective in the treatment of sewage sludge coming from an activated sludge system, although the method needs further study.

Chelating agents are organic compounds containing a metal ion in their structure. The addition of chelators, such as acid ethylenediamine tetraacetic acid (EDTA) and nitrilotriacetic acid (NTA), with the aim of removing metals from various substrates, such as sewage sludge, has also been studied, as they are considered excellent extractors (Deng et al. 2009). EDTA has been shown to be effective in removing metals, as well as having the advantage of being recoverable after the reaction (Sun et al. 2001).

The application of a less common type of chelator, diacetic/glutamic acid (GLDA), for the removal of different metals was investigated by Wu et al. (2015), who obtained satisfactory values with removal percentages above $80 \%$ for $\mathrm{Ni}, \mathrm{Cd}$, and $\mathrm{Cu}$ (Table 1). These authors claim that replacing the traditionally used chelating is recommended as this type of chemical reagent presents a high risk of leaching of the metals present in the substrate, and subsequent contamination of the groundwater. Unlike other chelating agents mentioned, GLDA is biodegradable and therefore a more environmentally advantageous alternative.

\subsection{Physical Treatments}

Heat treatment is one of the most common physical treatments for a number of substrates contaminated with metals, and has been considered advantageous in relation to other treatments currently applied to sewage sludge, as the mobility and availability of many inorganic elements may alter ( $\mathrm{Li}$ et al. 2012) after treatment at $300-400{ }^{\circ} \mathrm{C}$, facilitating their removal (Shi et al. 2013). Some metals evaporate during the exposure of the substrate to high temperatures, and can be captured when present in the ash or condensed when present in the evaporated water (Zorpas et al. 2001).

The higher the temperature applied, the greater the leaching of metals. At the same time, higher temperatures result in a greater loss of organic matter and nutrients, which prevents their subsequent application as fertilizer (Shi et al. 2013; Obrador et al. 2001). However, an advantage related to the degradation capacity of organic molecules at high temperatures is the consequent elimination of potential organic pollutants (Zorpas et al. 2001).

It can be seen that heat treatment requires a shorter exposure time (Table 1), and can almost completely remove the metals $\mathrm{Cd}$ and $\mathrm{Cu}$ (94 and $97 \%$, respectively) in only $1 \mathrm{~h}$ of hydrothermal treatment (with the addition of rice husk to the substrate) (Shi et al. 2013). However, to achieve the temperatures required by this system, there is a need for large amounts of energy and physical space, as well as a risk of secondary pollution by thermal pollution, which raises questions about the cost and benefits of this option.

Electroremediation, an alternative to chemical and traditional physical methods, has been widely studied in the last decade. The principle of this method is the application of a low electric current directly to the substrate or the application of a potential between electrodes on the substrate. In this way, contaminants can become charged, mineralized and mobile, facilitating their removal (Elicker et al. 2014).

Despite having been conducted only on a pilot scale, electroremediation techniques such as electrokinetic and electrodialysis, are considered promising for the removal of substrates contaminated with metals, such as water, soil, and sludge (Ebbers et al. 2015; Wang et al. 2005), as electroremediation was originally developed for the remediation of contaminated soils (Niroumand et al. 2012). The main advantages of this kind of treatment include the short exposure time period, which usually lasts only hours, and the possibility of recovering metals from the substrate (Elicker et al. 2014).

Electrokinesis is based on three main mechanisms: (1) the electromigration of ionic species charged in the electric field of the substrate, where cations migrate towards the cathode and, similarly, anions towards the anode; (2) electrosmosis, which is the transport of fluids through capillaries, caused due to differences in electric potential, with the pores of the solid substrate such as soil or sludge corresponding to capillaries; and (3) electrophoresis - migration in a solution of ions or charged colloidal particles through the application of an external electric potential (Niroumand et al. 2012). Briefly, the basis of the electrokinetic process are the analytes of interest, in this case the metals, which are charged and 
solubilized and remain in the liquid phase, and can then be retrieved in the future.

According to Niroumand et al. (2012), the separation of water occurs at the anode through the reaction described in Eqs. 1-2, while mobilization is enhanced by $\mathrm{pH}$ changes in the sediment during treatment.

Cathode : $4 \mathrm{H}_{2} \mathrm{O}+4 e^{-} \rightarrow 2 \mathrm{H}_{2(g)}+4 \mathrm{OH}^{-}$

Anode $: 2 \mathrm{H}_{2} \mathrm{O} \rightarrow \mathrm{O}_{2(g)}+4 \mathrm{H}^{+}+4 e^{-9}$

Although electrodialysis has revealed itself to be suitable for removing some metals, especially $\mathrm{Zn}$ $(85 \%)$ and $\mathrm{Ni}(56 \%)$, and also for the recovery of phosphorus from sludge, this method appears to be most effective under acid conditions, with $\mathrm{pH}$ values near 3.7 (Ebbers et al. 2015). The electrokinetic method, meanwhile, is more efficient when the material is pre-acidified with nitric acid at $\mathrm{pH} 2.0$ (Wang et al. 2005).

Wang et al. (2005) found that the electrokinetic technique was effective in removing the metals $\mathrm{Zn}$, $\mathrm{Ni}$, and $\mathrm{Cu}$, with removal percentages above $90 \%$. However, the same was not observed for the removal of $\mathrm{Pb}$, where the authors obtained removal values of only $19 \%$. In addition, there was also a need for acidification of sewage sludge.

Although some authors, such as Elicker et al. (2014), claim that one of the advantages of electroremediation techniques is that they do not require the addition of toxic chemicals, the opposite has been observed in some works, such as Ebbers et al. (2015) and Wang et al. (2005) where electroremediation methods require a low $\mathrm{pH}$ in order to function, that is, it requires preacidification of the substrate with chemicals, which can compromise its cost-benefit and also cause damage to the environment.

\subsection{Biological Treatments}

\subsubsection{Vermicomposting}

Earthworms (order: Haplotaxida) are considered important bioindicators, as they are sensitive to pollutants, including metals. Thus, the vermicomposting technique is nothing more than the improvement of the widely known process of bioaccumulation of metals in living tissues (Azizi et al. 2013; Domínguez-Crespo et al. 2012).

During the vermicomposting process, earthworms ingest and digest waste with the help of a rich intestinal microbiota, excreting a humidified material, which is homogeneous and low in pollutants (Suthar et al. 2014). Eisenia fetida is the most studied species in this process due to its biological characteristics of being easy to cultivate and also because there is already considerable data on its biology and ecotoxicology (Domínguez-Crespo et al. 2012).

A study on the potential removal of toxic metal by bioaccumulation by Lumbricus rubellus in a composter containing $20 \%$ of sewage sludge and $80 \%$ of waste manure for mushrooms, indicated that while the results obtained for the removal of metals were considerably satisfactory, reaching values of $88 \%$ of $\mathrm{Cu}, 81 \%$ of $\mathrm{Cr}$ and maximum $97 \%$ of $\mathrm{Pb}$, the exposure time required was too long, reaching 105 days, when the worms had to be removed from the composter, preventing the excretion of ingested metal back into the substrate (Azizi et al. 2013).

Apart from the potential for removing metals and other potentially toxic substances, Suthar et al. (2014) also indicated that the inoculation of some worms such as E. fetida can be considered a promising biomarker for the quality of waste-in this case the sludge formed after the treatment of wastewater from the paper industry - as their growth pattern and period of breeding and incubation are directly related to the characteristics of the substrate. In this work, the authors analyzed the $\mathrm{Cd}, \mathrm{Cr}, \mathrm{Cu}$, and $\mathrm{Pb}$ removal potential of E. fetida, obtaining maximum percentages of removal of $37,80.9$, 88.4 , and $97.5 \%$, respectively.

Vermicomposting is also used for the stabilization of sewage sludge, as the worms eventually reduce organic carbon concentrations and increase phosphorus concentration, improving the quality of the waste as fertilizer (Cieslik et al. 2015).

Despite the apparent efficiency of this technique, which has a high potential for removing metals without negatively altering the nutrient composition of the substrate and does not exhibit high costs, there is few data in literature on this process (Suthar et al. 2014). It is possible to speculate that the lack of interest in relation to this technique 
occurs due to the long exposure time needed (between 70 and 90 days), (Azizi et al. 2013; Domínguez-Crespo et al. 2012) especially when compared to other types of treatments, in order to achieve similar metal removal efficiency. Moreover, there is no data in literature on the allocation of worms contaminated with toxic metals after the vermicomposting process.

\subsubsection{Biosurfactant Application}

Surfactants are amphiphilic compounds that have hydrophobic and hydrophilic domains capable of reducing surface tension and interfacial tension between the molecules on the interface between immiscible fluids. The use of biosurfactants, which are similar substances, but are extracellularly produced by some microorganisms, instead of petroleum-derived surfactants is gaining prominence as it causes less harm to the environment (Franzetti et al. 2014).

Biological methods for the removal of metals are important in soil, water, and sludge remediation, as the microorganisms can also interact with and affect the properties of many toxic metals (Franzetti et al. 2014). The addition of biosurfactants is a biological method that has been used for the removal of metals on various substrates, as these substances tend to interact with poorly soluble contaminants and transfer to the aqueous phase, which enables their subsequent removal, as heteroatoms are commonly present in the biosurfactant structure, and many of their functional groups (hydroxyl, carbonyl, amine, etc.) may form complexes with the toxic metal ions, facilitating metal removal (Lawniczak et al. 2013).

There is still little data available in literature on the removal of metals in sewage sludge by the addition of biosurfactants, in comparison with other types of treatment. Nevertheless, Maier et al. (2001) studied the recovery potential of $\mathrm{Cu}$ in anaerobic sewage sludges, obtaining satisfactory recovery results recovery of $59.4 \%$ by treatment with $50 \mathrm{mM}$ rhamnolipids for $24 \mathrm{~h}$.

The use of this kind of treatment on soil has already been studied, such as by Yang et al. (2016), who used glycolipids produced by Burkholderia sp. to remove $\mathrm{Zn}, \mathrm{Pb}, \mathrm{Mn}, \mathrm{Cd}$, and $\mathrm{Cu}$. The results of this study indicate the need for more studies on the potential of this type of treatment for sewage sludge, as it has shown good results with soils and some types of metals in sludge. There is still, however, a need to identify what types of biosurfactants are more efficient for each type of substrate and metal, as well as the conditions necessary for the proper functioning of this process.

\subsubsection{Bioleaching}

Microbial activity is one of the factors that can alter the form of metals, as the redox indicator systems performed by some microorganisms in order to obtain energy can change the mobility of these elements (Picardal and Cooper 2005). Thus, bioleaching utilizes the catalytic effect produced by the metabolic activity of the microorganisms, oxidizing iron and sulfur (Pathak et al. 2009). This technique has been studied for the removal of metals in sewage sludge, river dredged sediments, and soils. In the case of sewage sludge, the bioleaching process did not compromise the sludge properties such as a conditioner and fertilizer of soil (Fang et al. 2011). This technique has displayed promise in the removal of metals as it is simple, efficient, and economically viable (Fang and Zhou 2007).

The presence of high amounts of organic matter and organic acids in the sewage sludge can compromise the effectiveness of the bioleaching process (Fournier et al. 1998), which may be the reason for not using this substrate in comparison to others, such as soil and dredged sediment of rivers. However, a possible alternative would be the use of anaerobic and digested sewage sludge, due to the fact that these substances present a lower level of organic matter content (Andreoli 2001).

Several microorganisms are known to act in bioleaching, but two species of acidophilus bacteria of Acidithiobacillus genus, A. ferrooxidans and A. thiooxidans are the most used in this process (Fang and Zhou 2007; Pathak et al. 2009). These bacteria oxidize reduced sulfur (elemental sulfur or sulfur compounds) to sulfuric acid and acidify the medium, providing favorable conditions for solubilization of the metals (Mishra and Rhee 2014).

The solubilization of $\mathrm{Cu}, \mathrm{Zn}, \mathrm{Cd}, \mathrm{Mn}$, and $\mathrm{Ni}$ in different sewage sludges was satisfactory (over $80 \%$ ) in the bioleaching process using A. ferroxidans and $\mathrm{FeSO} 4 \cdot 7 \mathrm{H} 2 \mathrm{O}$ as an energy source after a period of 10 days (Xiang et al. 
2000). Likewise, the use of $A$. thiooxidans and $S^{0}$ as an energy source was also effective in the solubilization of metals from sewage sludges, reaching 43.6, 92.2, 41.6, and $96.5 \% \mathrm{Cr}, \mathrm{Cu}, \mathrm{Pb}$, and $\mathrm{Zn}$, respectively (Wen et al. 2012).

Microbial activity may affect metal ions in a direct and an indirect manner. In the direct manner, the microorganism uses the metal to perform redox reactions, changing their sorptive properties, species, and solubility; while in the indirect manner, the redox reactions do not occur directly through the metal as a source of electrons, but through other species, although these reactions can cause changes in the acidity of the substrate or even generate new species that can react with the metal ions present and change its initial characteristics (Picardal and Cooper 2005).

It is possible to observe an example of the direct mechanism in Eq. 3, where sulfides are oxidized directly into soluble metal sulfates $(\mathrm{Me})$,

$\mathrm{MeS}+2 \mathrm{O}_{2} \rightarrow \mathrm{MeSO}_{4}$

In Eqs. 4-5, it is possible to observe an example of an indirect mechanism of metal solubilization by the oxidation of reduced sulfur compounds or elemental sulfur $\left(\mathrm{S}^{0}\right)$, where metal $(\mathrm{Me})$ solubilization occurs due to the reduction in $\mathrm{pH}$, caused by the reaction described in Eq. 4 (Pathak et al. 2009).

$\mathrm{S}^{0}+\mathrm{H}_{2} \mathrm{O}+1.5 \mathrm{O}_{2} \rightarrow \mathrm{H}_{2} \mathrm{SO}_{4}$

$\mathrm{H}_{2} \mathrm{SO}_{4}+$ sludge $+\mathrm{Me} \rightarrow$ sludge $-2 \mathrm{H}+\mathrm{MeSO}_{4}$

In the same way, the direct mechanism of metal solubilization from iron compounds by A. ferrooxidans occurs in accordance with Eq. 6, in which the metal is directly oxidized by the microorganism, while in Eqs. 7-8 its indirect mechanism is described, in which a product of the reaction (Eq. 7), $\mathrm{Fe}_{2}\left(\mathrm{SO}_{4}\right)_{3}$ serves as a substrate for a further reaction (Eq. 8), which has $\mathrm{H}_{2} \mathrm{SO}_{4}$ as one of its final products. It is noteworthy that $\mathrm{H}_{2} \mathrm{SO}_{4}$ is also the substrate of the first reaction in the indirect mechanism (Eq. 7). This mechanism can therefore be considered as cyclic, acidifying the medium in each reaction and solubilizing more metals due to this acidity (Pathak et al. 2009).

$$
\mathrm{MeS}+2 \mathrm{O}_{2} \rightarrow \mathrm{MeSO}_{4}
$$

$$
2 \mathrm{FeSO}_{4}+0.5 \mathrm{O}_{2}+\mathrm{H}_{2} \mathrm{SO}_{4} \rightarrow \mathrm{Fe}_{2}\left(\mathrm{SO}_{4}\right)_{3}+\mathrm{H}_{2} \mathrm{O}
$$

$$
\begin{gathered}
4 \mathrm{Fe}_{2}\left(\mathrm{SO}_{4}\right)_{3}+2 \mathrm{MeS}+4 \mathrm{H}_{2} \mathrm{O}+2 \mathrm{O}_{2} \rightarrow 2 \mathrm{Me}^{2+} \\
+2 \mathrm{SO}_{4}{ }^{2-}+8 \mathrm{FeSO}_{4}+4 \mathrm{H}_{2} \mathrm{SO}_{4}
\end{gathered}
$$

\subsection{Alternative Treatments}

As there is still no consensus on the most effective method for removing sewage sludge metals, and considering that all the exposed alternatives have both advantages (Fig. 2) and limitations, one alternative that has been discussed recently is the simultaneous use of more than one type of treatment.

The agility of the process, or in other words the short time of substrate exposure needed, is an important factor to be considered, as the higher the exposure time of the sludge to acidic conditions, the greater its loss of nutrients (Pathak et al. 2009). Biological methods should not be discarded because of the higher treatment time needed. Instead, it is necessary to seek methods of metal removal that: require less exposure time and are less harmful to nutrients present in the sludge; have a low cost; and also have less impact on the environment.

A good example of this is the conciliation between the bioleaching method using acidophilus microorganisms and the use of biosurfactants. The presence of organic acids such as formic, propionic, hexanoic, and succinic, together with the dissolved organic matter in the sludge strongly inhibits the growth of Acidithiobacillus, resulting in delays in the bioleaching processes (Zhou et al. 2013).

Heterotrophic microorganisms have been studied as an alternative to reducing the concentration of organic acids present in the sludge. Fournier et al. (1998) showed that the presence of Rhodotorula yeasts was able to reduce the incubation time required for the growth of A. ferrooxidans. It is noteworthy that a large number of heterotrophic microorganisms can metabolize organic compounds into energy and carbon sources for growth, establishing a mutualistic relationship with the bacteria involved in bioleaching.

The co-inoculation of yeasts of the genera Galactomyces and Acidithiobacillus increased the 
Fig. 2 Comparison of the main qualities of the chemical, physical, and biological treatments. The intersections show common qualities between treatments. Both the efficiency and the exposure time are related to the removal of metals

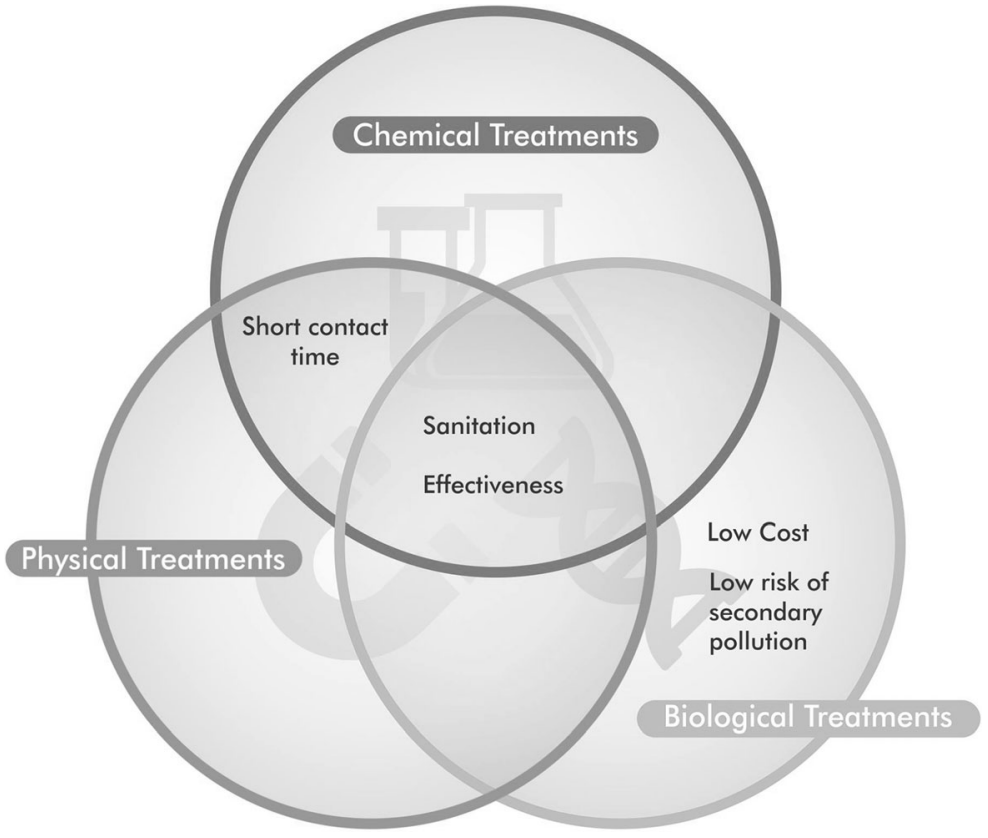

bioleaching efficiency of sewage sludge, wherein the yeast consumed some organic acids and the performance of Acidithiobacillus species was more efficient, increasing from 82 to $92 \%$ for $\mathrm{Cu}$ and $\mathrm{Zn}$ in the coinoculation tests and 64 to $84 \%$ for $\mathrm{Cu}$ and $\mathrm{Zn}$ in the same period of $132 \mathrm{~h}$. This is because this genus of yeast is able to produce biosurfactants and the presence of these compounds can accelerate sulfur oxidation rate by A. thiooxidans, increasing their solubility (Zhou et al. 2013). Furthermore, it is known that toxic metals may be solubilized by the application of biosurfactants (Banat et al. 2010).

It is therefore possible to indicate three large main advantages of the co-inoculation of biosurfactantproducing yeasts and bacteria involved in the bioleaching process: (1) the consumption of organic acids which retard the growth of Acidithiobacillus; (2) the increased solubility of sulfur due to biosurfactant production; and (3) an increase in the solubilization of the metals.

It is possible to speculate about the combination of other methods, such as bioleaching and electroremediation, but one of the limiting factors is the need for pre-acidification of the substrate before treatment, which may increase costs and the risks of secondary pollution. Unfortunately, data in literature on the combination of two or more methods of removing sewage sludge metals is scarce.

\section{Conclusions}

The application of sewage sludge as a fertilizer has been found to be the most appropriate disposal method for this waste, both economically and environmentally. Thus, the treatment of sewage sludge can be regarded as a dual-purpose process.

The presence of toxic metals limits the disposal of sewage sludge on agricultural land. Toxic metals can be removed by different techniques (physical, chemical, and biological), but there is still no consensus on the best treatment option. Chemical and physical treatments may have a high risk of secondary pollution, and are usually very expensive.

Although biological methods have shown promising results in the removal of metals and are less harmful to the environment, they have only been studied on a pilot scale and are also more time consuming. Therefore, it is necessary to stimulate the search for new methods that are both environmentally and economically advantageous. 
Finally, it is important to note that even though the methods used cannot generate a final product that can be used as a fertilizer, the treatment of sewage sludge should not be overlooked, as its improper use is environmentally harmful. It should also be considered that the implementation of sewage sludge treatments can improve the physical characteristics of the soil, without influencing their nutritional characteristics.

Acknowledgments The authors would like to thanks the Programa de Pós Graduação em Biotecnologia e Monitoramento Ambiental (Graduate Program in Biotechnology and Environmental Monitoring) from Universidade Federal de São Carlos campus Sorocaba. This work was funded by the Conselho Nacional de Desenvolvimento Cientifico e Tecnológico (National Council for Scientific and Technological Development) (CNPq) (process numbers 442833/ 2014-8) and Coordenação de Aperfeiçoamento de Pessoal de Nivel Superior (Development Committee for Higher Education Personnel) (CAPES).

\section{References}

Andreoli, C. V. (2001). Sewage sludge: treatment and final disposal (Lodo de esgotos: Tratamento e disposição final) (1st ed., Vol. 6). Belo Horizonte: Departamento de Engenharia Sanitária e Ambiental.

Associação Brasileira de Nórmas Técnicas (ABNT) (2004). NBR 10004: Solid waste: classification (NBR 10004: Resíduos Sólidos: classificação). São Paulo: ABNT.

Azizi, A. B., Lim, M. P. M., Noor, Z. M., \& Abdullah, N. (2013). Vermiremoval of heavy metal in sewage sludge by utilising Lumbricus rubellus. Ecotoxicology and Environmental Safety, 90, 13-20.

Banat, I. M., Franzetti, A., Gandolfi, I., Bestetti, G., Martinotti, M. G., Fracchia, L., Smyth, T. J., \& Marchant, R. (2010). Microbial biosurfactants production, applications and future potential. Applied Microbiology and Biotechnology, 87, 427444.

Brasil (2010). Law $N^{\circ}$. 12.305 of August 2, 2010 - National Policy on Solid Waste (PNRS). (Lei $\mathrm{N}^{\circ} 12.305$ de 02 de agosto de 2010 - Política Nacional de Resíduos Sólidos- PNRS).

Chen, H., Yan, S.-H., Ye, Z.-L., Meng, H.-J., \& Zhu, Y.-G. (2012). Utilization of urban sewage sludge: Chinese perspectives. Environmental Sciences and Pollution Research, 19, 14541463.

Cheng, Y. X., Hua, Y. M., Zhang, S. H., \& Tiang, G. M. (2005). Transformation of heavy metal forms during sewage sludge bioleaching. Journal of Hazardous Materials, B123, 196202.

Cieslik, B. M., Namiesnik, J., \& Konieczka, P. (2015). Review of sewage sludge management: standards, regulations and analytical methods. Journal of Cleaner Production, 90, 1-15.

CONAMA, Conselho Nacional do Meio Ambiente (2006). Resolution No. 375. Criteria and procedures for the agricultural use of sewage sludge generated in sewage treatment plants and their derivatives, and other measures (Resolução $\mathrm{n}^{\circ}$ 375. Critérios e procedimentos para o uso agrícola de lodos de esgoto gerados em estações de tratamento de esgoto sanitário e seus produtos derivados, e dá outras providências).

Dabrowski, A., Hubicki, Z., Podkoscielny, \& Robens, E. (2004). Selective removal of the heavy metal ions from waters and industrial wastewaters by ion-exchange method. Chemosphere, 56, 91-106.

CETESB - Companhia de Tecnologia de Saneamento Ambiental (1999). Standard P4.230: Sludge Application of biological treatment systems in agricultural areas - Criteria for the design and operation (Norma P4.230: Aplicação de lodos de sistemas de tratamento biológico em áreas agrícolas Critérios para projeto e operação), São Paulo.

Deng, J., Feng, X., \& Qiu, X. (2009). Extraction of heavy metal from sewage sludge using ultrasound-assisted nitric acid. Chemical Engineering Journal, 152, 177-182.

Domínguez-Crespo, M. A., Sánchez-Hernandez, E. S., TorresHuerta, A. M., Negrete-Rodriguez, M. L. X., CondeBarajas, E., \& Flores-Vela, A. (2012). Effect of the heavy metals $\mathrm{Cu}, \mathrm{Ni}, \mathrm{Cd}$ and $\mathrm{Zn}$ on the growth and reproduction of epigeic earthworms (E. fetida) during the vermistabilization of municipal sewage sludge. Water, Air, \& Soil Pollution, 223, 915-931.

Ebbers, B., Ottosen, L. M., \& Jensen, P. E. (2015). Electrodialytic treatment of municipal wastewater and sludge for the removal of heavy metals and recovery of phosphorus. Electrochimica Acta, 181, 90-99.

Elicker, C., Sanches-Filho, P. J., \& Castagno, R. L. (2014). Electroremediation of heavy metals in sewage sludge. Brazilian Journal of Chemical Engineering, 31(02), 365371.

Fang, D., \& Zhou, L. X. (2007). Enhanced Cr bioleaching efficiency from tannery sludge with coinoculation of Acidithiobacillus thiooxidans TS6 and Brettanomyces B65 in an air-lift reactor. Chemosphere, 69, 303-310.

Fang, D., Zhang, R., Zhou, L., \& Li, J. (2011). A combination of bioleaching and bioprecipitation for deep removal of contaminating metals from dredged sediment. Journal of Hazardous Materials, 192, 226-233.

Fournier, D., Lemieux, R., \& Couillard, D. (1998). Essential interactions between Thiobacillus ferrooxidans and heterotrophic microorganisms during a wastewater sludge bioleaching process. Environmental Pollution, 101, 303309.

Franzetti, A., Gandolfi, I., Fracchia, L., Van Hamme, J., Gkorezis, P., Marchant, R., \& Banat, I. M. (2014). Biosurfactant use in heavy metal removal from industrial effluents and contaminated sites. In N. Kosaric \& F. Vadar-Sukan (Eds.), Biosurfactants: Production and utilization-Processes, technologies, and economics (2nd ed.). Nova Iorque: CRC Press.

Fuerhacker, M., Haile, T. M., Kogelnig, D., Stojanovic, A., \& Keppler, B. (2012). Application of ionic liquids for the removal of heavy metals from wastewater and activated sludge. Water Science \& Technology, 65(10), 1765-1773.

Jjemba, P. K. (2005). Bioavailability of metals and metalloids in terrestrial environments. In I. Ahmad, S. Hayat, \& J. Pichtel (Eds.), Heavy metal contamination of soil: Problems and remedies (pp. 25-41). New Hampshire: Science Publishers. 
Kelessidis, A., \& Stasinakis, A. S. (2012). Comparative study of the methods used for treatment and final disposal of sewage sludge in European countries. Waste Management, 32, 11861195 .

Lawniczak, L., Marecik, R., \& Chrzanowski, L. (2013). Contributions of biosurfactants to natural or induced bioremediation. Applied Microbiology and Biotechnology, 97, 2327-2339.

Li, L., Xu, Z. R., Zhang, C., Bao, J., \& Dai, X. (2012). Quantitative evaluation of heavy metals in solid residues from sub- and super- critical water gasification of sewage sludge. Bioresource Technonogy, 121, 169-175.

Maier, R. M., Neilson, J. W., Artiola, J. F., Jordan, F. L., Glenn, E. P., \& Descher, S. M. (2001). Remediation of metal- contaminated soil and sludge using biosurfactant technology. International Journal of Occupational Medicine and Environmental Health, 13(3), 241-248.

Mishra, D., \& Rhee, Y. H. (2014). Microbial leaching of metals from solid industrial wastes. Journal of Microbiology, 52(01), 1-7.

Niroumand, H., Nazir, R., \& Kassim, K. A. (2012). The performance of electrochemical remediation technologies in soil mechanics. International Journal of Electrochemical Science, 7, 5708-5715.

Obrador, A., Rico, M. I., Alvarez, J. M., \& Novillo, J. (2001). Infuence of thermal treatment on sequential extraction and leaching behaviour of trace metals in a contaminated sewage sludge. Bioresource Technology, 76, 259-264.

Oliver, B. G., \& Cosgrove, E. G. (1974). The efficiency of heavy metal removal by a conventional activated sludge treatment plant. Water Research, 8(11), 869-874.

Pathak, A., Dastidar, M. G., \& Sreekrishnan, T. R. (2009). Bioleaching of heavy metals from sewage: a review. Journal of Environmental Management, 90, 2343-2353.

Picardal, F., \& Cooper, D. C. (2005). Microbially mediated changes in the mobility of contaminant metals in soils and sediments. In I. Ahmad, S. Hayat, \& J. Pichtel (Eds.), Heavy metal contamination of soil: Problems and remedies (pp. 4388). New Hampshire: Science Publishers.

Qi-Tang, W., Pascasie, N., Ce-Hui, M., \& Yi, L. (1998). Removal of heavy metals from sewage sludge by low costing chemical method and recycling in agriculture. Journal of Environmental Sciences, 10(01), 122-128.

Shi, W., Liu, C., Ding, D., Lei, Z., Yang, Z., Yang, Y., Feng, C., \& Zhang, Z. (2013). Immobilization of heavy metals in sewage sludge by using subcritical water technology. Bioresource Technology, 137, 18-24.

Sun, B., Zhao, F. J., Lombi, E., \& McGrath, S. P. (2001). Leaching of heavy metals from contaminated soils using EDTA. Environmental Pollution, 113, 111-120.

Suthar, S., Sajwan, P., \& Kumar, K. (2014). Vermiremediation of heavy metals in wastewater sludge from paper and pulp industry using earthworm Eisenia fetida. Ecotoxicology and Environmental Safety, 109, 177-184.

Villar, L. D., \& Garcia, O., Jr. (2003). Assessment of anaerobic sewage sludge quality for agricultural application after metal bioleaching. Environmental Technology, 24(12), 1553-1559.

Wang, J. Y., Zhang, D. S., Stabnikova, O., \& Tay, J. H. (2005). Evaluation of electrokinetic removal of heavy metals from sewage sludge. Journal of Hazardous Materials, 124, 139146.

Wei, Z., Liu, Y., Ai-He, W., Cai-Wen, W., \& Jun, Z. (2014). Advance of sludge producing, hazards and disposal methods. Advanced Meterials Research, 1033-1034, 369-377.

Wen, Y.-M., Wang, Q.-P., Tang, C., \& Chen, Z.-L. (2012). Bioleaching of heavy metals from sewage sludge by Acidithiobacillus thiooxidans - a comparative study. Journal of Soils and Sediments, 12, 900-908.

Wen, Y.-M., Cheng, Y., Tang, C., \& Chen, Z.-L. (2013). Bioleaching of heavy metals from sewage sludge using indigenous iron-oxidizing microorganisms. Journal of Soils and Sediments, 13, 166-175.

Wong, P. K. (2005). Practical issues of land application of biosolids. In I. Ahmad, S. Hayat, \& J. Pichtel (Eds.), Heavy metal contamination of soil: Problems and remedies (pp. 123). New Hampshire: Science Publishers.

Wong, J. W. C., Xiang, L., Gu, X. Y., \& Zhou, L. X. (2004). Bioleaching of heavy metals from anaerobically digested sewage sludge using $\mathrm{FeS}_{2}$ as an energy source. Chemosphere, 55, 101-107.

Wu, Q., Cui, Y., Li, Q., \& Sun, J. (2015). Effective removal of heavy metals from industrial sludge with the aid of a biodegradable chelating ligand GLDA. Journal of Hazardous Materials, 283, 748-754.

Xiang, L., Chan, L. C., Wong, J. W. C. (2000). Removal of heavy metals from anaerobically digested sewage sludge by isolated indigenous iron oxidizing bacteria. Chemosphere, 41, 283287.

Yang, Z., Zhang, Z., Chai, L., Wang, Y., Liu, Y., \& Xiao, R. (2016). Bioleaching remediation of heavy metalcontaminated soils using Burkholderia sp. Z-90. Journal of Hazardous Materials, 301, 145-152.

Zhou, J., Zheng, G. Y., Zhou, L. X., Liu, F. W., Zheng, C. C., \& Cui, C. H. (2013). Degradation of inhibitory substances in sludge by Galactomyces sp. Z3 and the role of its extracellular polymeric substances in improving bioleaching. Bioresource Technology, 132, 217-223.

Zorpas, A. A., Vlyssides, A. G., Zorpas, G. A., Karlis, P. K., \& Arapoglou, D. (2001). Impact of thermal treatment on metal in sewage sludge from the Psittalias wastewater treatment plant, Athens, Greece. Journal of Hazardous Materials, B82, 291-298. 